\title{
Digital System for Customs Inspection of Baggage in High Security Areas
}

\author{
Victoria Bulaga \\ ORCID 0000-0001-9655-6684 \\ Department of Computer Radio Engineering and Technical Information Security Systems \\ Kharkiv National University of Radio Electronics \\ Kharkiv, Ukraine \\ victoria.bulaga@nure.ua
}

\begin{abstract}
This article discusses the development of a threeenergy digital system for customs inspection of luggage and hand luggage in airports and high-security areas, which will provide not only easy monitoring of luggage and hand luggage, but also security screening. The peculiarity of such a system is the use of scintillation crystals in the control systems of customs baggage inspection. And also the scheme of threeenergy digital radiographic system has been developed, which gives the possibility of fast and safe luggage monitoring.
\end{abstract}

Keywords-digital customs control system, scintillation crystals, detector, security, controlled area.

\section{INTRODUCTION}

The Ukrainian customs service plays an important role in the regulation of the country's foreign trade. Its main task is to ensure compliance with the measures of customs and tariff regulation, as well as to create conditions conducive to accelerating the turnover of goods across the customs border. Accordingly, the customs border is one of the places with a high concentration of people, which leads to the need for increased vigilance and increased safety measures. Thirst for profit, unemployment, the opportunity to earn "easy money", all this encourages people to commit crimes, to illegally import and export prohibited goods across the border. Which, in particular, may entail damage not only to an individual entity, but also lead to an international conflict. For example, careless, inept work at the customs border can lead to the hijacking of aircraft and the death of people. In contrast to the activities of intruders and military groups, the customs services present a set of measures and means to protect the border from unauthorized import and export of contraband. The complex includes the latest developments in engineering and technical means, regulatory legal acts, the work of the reaction forces, the work of operators of detection devices and much more, which in total makes it possible to timely detect, seize and dispose of contraband.

The globalization of the economy, the possibility of using modern information technologies induce the Ukrainian customs service to change its procedures and rules for conducting customs control, taking into account the ongoing changes and determine the strategy of customs control based on the system of risk assessment measures.

To conduct the study, the goal was set - to determine the current state, problems of use and directions for the further development of technical means of customs control
Therefore, the tasks of the study are:

- determination of the range of problems associated with the development and implementation of the developed system $\{\{1\}\}$ - analysis of the modern technical means of customs control;

- calculation of the preamplifier;

- development and calculation of the economic component and the safety of human life.

In modern conditions, the customs service, on the one hand, it should ensure the interests of the state in the field of foreign trade, counteract threats to national security, and on the other, create favorable conditions for participants in foreign economic activity. These principles are laid down in the Concept for the development of customs authorities, which leads to constant modernization and replacement of existing equipment, which in turn confirms the relevance of development in the field of information security, in particular, scanning systems.

\section{TYPES OF SCANNING INTROSCOPES FOR BAGGAGE INSPECTION}

When transporting prohibited and dangerous goods for their inspection at borders and at airports, scanning X-ray nitroscopic systems are used to control baggage and carry-on baggage. At the same time, the requirements for this device are highly sensitive electronics, efficient radiation detectors, precision mechanics, and modern software. A line of detectors of the STs-FD type is used as a receiving device. A distinctive feature for most types of Ukrainian scanners is their dual energy with the use of two lines of detectors. The low-energy line contains exclusive crystals.

Considering digital radiography using only X-ray and Yradiation, three most common and widely used types of systems can be distinguished.

- Digital radiographs using luminescent screens with subsequent transformation of light through an optical system and registration on a CCD matrix

- Digital flat panel radiographs based on amorphous silicon.

- Digital radiographs using a line of detectors of the STs-FD type - up to 1024 detectors in the line. 
The table (p. 356) shows the comparative parameters of these systems. It can be seen from the table that the system with a line of SC-PD detectors, being significantly inferior to the first two types in terms of resolution, is much superior to them in contrast sensitivity, as well as in the linear portion of the dynamic range (4-5 orders of magnitude). different types of objects - from miniature microcircuits, the equivalent of a steel thickness of several hundred microns, to heavy vans with the possibility of shining through in the equivalent of a steel thickness of 350-400 mm.

\section{FEATURES OF DUAL- AND MULTI-ENERGY DIGITAL RADIOGRAPHY}

The use of the principle of two-energy detection opens up new possibilities for digital radiography. Increasing the information content due to the identification of areas with a given chemical composition in the controlled object. This is achieved due to the definition of.

\section{APPOINTMENT OF SCANNING INTROSCOPES FOR INSPECTION OF BAGGAGE, HAND LUGGAGE}

The baggage screening system is designed for customs control of hand luggage and passengers' baggage in order to identify items prohibited or restricted for movement across the state border, and provides:

- High-quality visual inspection of the contents of the baggage without opening it, distinguishing between organic and inorganic substances.

- Radiation level safe for humans, close to the natural background.

- High control performance.

- Radiation dose safe for photosensitive materials.

- A wide range of services for the operator.

\section{THE PRINCIPLE OF OPERATION OF THE SCANNING}

\section{SYSTEM FOR INSPECTION OF BAGGAGE, HAND LUGGAGE}

The X-ray introscopic complex for transport and baggage control is designed to control the operational display on the monitor screen of the shadow image of the controlled object and the items inside it, to identify prohibited attachments. A shadow X-ray introscopic image is formed as follows:

- The object of control (container or van) with the help of a transport platform moves through one plane of $\mathrm{X}$-ray beams in a direction perpendicular to these planes, the radiation source is a linear electron accelerator with a target-type device.

- X-rays, attenuated depending on the properties of the material and its thickness, falling on the detectors located in the horizontal and vertical rulers, are converted into electrical signals.

- Electrical signals are amplified, converted and digitally transmitted to a PC.

- The PC, according to a special program, processes the information received and forms a shadow image of the inspected object of control (OC).

\section{THE COMPOSITION OF THE SCANNING SYSTEM FOR INSPECTION OF BAGGAGE, HAND LUGGAGE}

$\mathrm{X}$-ray introscopic complex for control and inspection of customs cargo includes:

- $\quad$ Radiation system (SR).

- Detection and information processing system (SDOI).

- Object transportation system (STO).

- $\quad$ Radiation monitoring system (SRM).

- Control system (CS).

- $\quad$ Power supply system (SES).

Radiation system functions. An image of the controlled object is formed in Y-rays with the maximum possible equivalent of the thickness over steel.

Functions of the system for detecting and processing information. In the system for detecting and processing information, X-ray radiation, attenuated depending on the properties of the material and its thickness, falling on the detectors located in the horizontal and vertical rulers, are converted into electrical signals. Then, using the control system, synchronizing signals for polling the detector lines and the amplification factor of the signals taken from the detectors are generated.

Functions of the object transportation system. The controlled object is moved through the aspect planes of $\mathrm{X}$ ray beams along the transport platform.

Functions of the radiation monitoring system. Requirements for the safety of operation of the X-ray nitroscopic complex and the presence of a high level of hard $\mathrm{X}$-ray radiation make it necessary to include a radiation monitoring system in the complex. The control PC through the control system collects information from the sensors of direct and scattered Y-radiation, sensors of neutron radiation and radiation of the object, and, if necessary, through the sound and light alarm system, makes the appropriate notification.

Functions of the control system. The control system of the X-ray introscopic complex provides control of the operating modes of the complex, monitors the functioning of the complex and ensures safe operation:

- Control of impulse power supply of the X-ray accelerator

- Control and control of the rotation of the forming Xray beam of the collimator.

- Control of vacuum maintenance in the accelerator.

- Control of the auto-tuning of the frequency of the accelerator pump magnetrons.

- Monitoring and control of the power supply system of the radiant installations.

All systems of the complex are connected by means of a local information and computer network with centralized control. The control system is organized in the form of a network with parallel connection of controlled devices to the 
control processor based on the RS-485 serial data exchange interface.

The block diagram of the hardware is shown in the figure It consists of the following structural units: $\{\{1\}\}$ :

- Control PC.

- Controllers of management (KU) of peripheral devices (PU).

- $\quad$ Matched active plugs (AZ).

\section{FeAtures of DUAL- AND MULTI-ENERGY DigitAL RADIOGRAPHY}

The use of the principle of two-energy detection opens up new possibilities for digital radiography. Increasing information content by identifying areas with a given chemical composition in a controlled object. This is achieved due to the determination of the attenuation coefficients of the test object materials for two different radiation energies. There is one emitter, but the supply of two different voltages to the tube is modulated. The line of detectors is one, but the signal is registered synchronously for different voltages per emitter. This technology provides high detection rates with good throughput.

Five independent fan-shaped X-rays shine through each piece of baggage. Three $\mathrm{x}$-ray sources, mounted in a specific position, generate $\mathrm{x}$-rays at five different angles. These five radiation angles provide the information you need to provide the highest level of detection. Connection to a common computer network unites all the necessary system components of the system and provides a variety of information in the shortest possible time. Since it is about security, decisions must be made immediately.

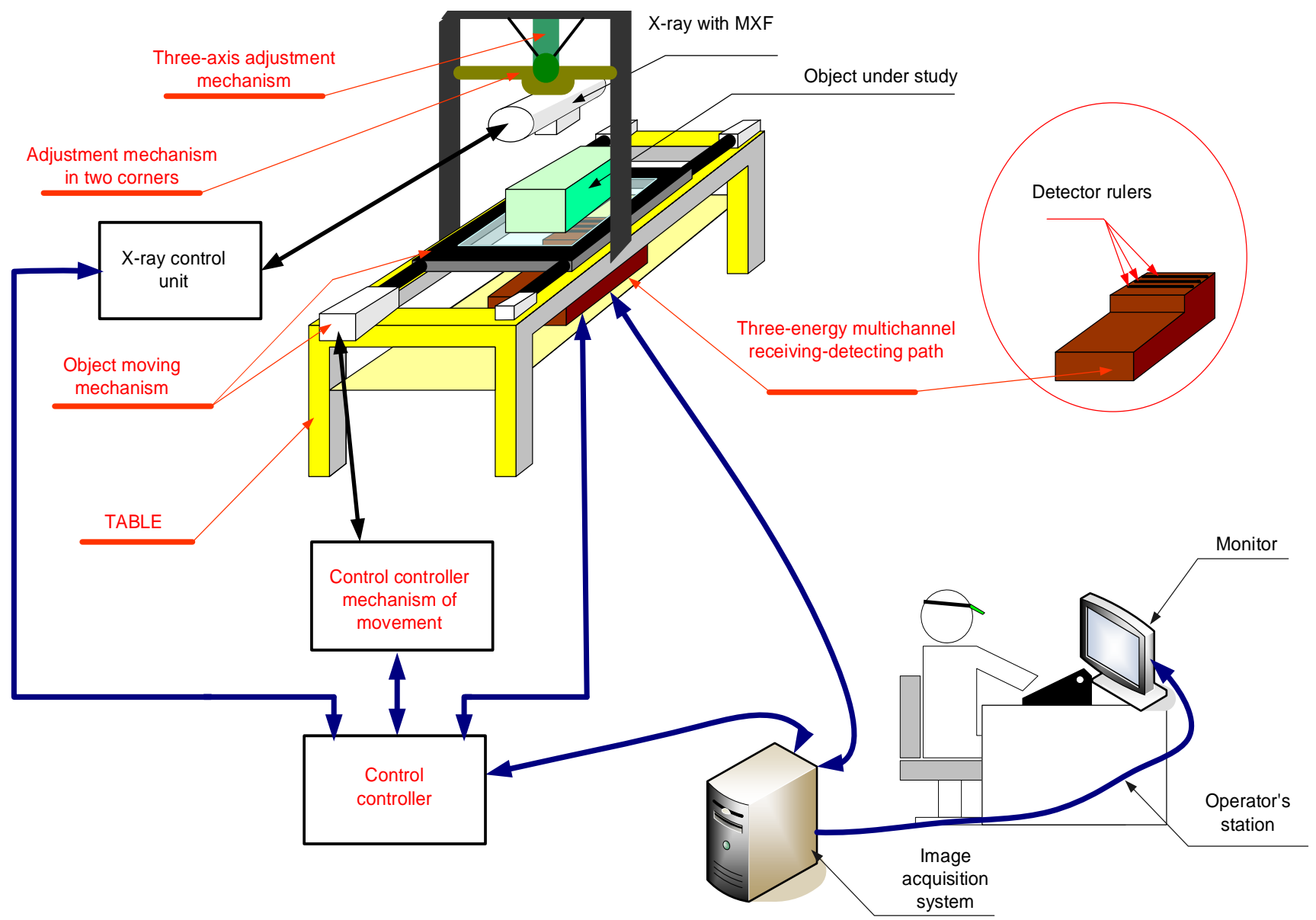

Fig. 1. Block diagram of a three-energy digital radiographic system.

\section{VIII.CONCLUSIONS}

At the present stage of development of society, people have not yet learned to restrain their passion for easy money, so the number of violations of the customs code will only grow.
The hard work of ensuring security falls on the shoulders of ordinary border and customs officials. The lives of many people depend on their immediate actions and efficiency.

In the conditions of the market and competition, entrepreneurship and technology keep pace with the times. 
The leakage of classified information leads to catastrophic consequences, so in the new conditions there is a mass problems associated with ensuring the safety and transportation of baggage.

Technical means of information protection come to the rescue in the difficult struggle for the preservation of borders.

Science and technology does not stand still and the capabilities of attackers practically do not have borders, the latest technologies allow them to come up with all the more perfect methods of smuggling. That is precisely why workers in the field of developing technical means of protecting information will always have a job.

\section{REFERENCES}

[1] O. Melnyk, M. Adamiv and A. Todoshchuk, "Conceptual Principles of Reforming the Customs System of Ukraine in Terms of European Integration", Ekonomika ta derzhava, no. 11, p. 39, 2018. doi: 10.32702/2306-6806.2018.11.39.

[2] I. Nestoryshen and V. Turzhanskyi, "Profiling Customs Risks in the Customs Security System of Ukraine", The Collection of Scientific Works of Kirovohrad National Technical University. Economic Sciences, no. 33, pp. 9-16, 2018. doi: 10.32515/2413-340x.2018.33.916.

[3] L. Kyyda, "The Adaptation of Customs Legislation to the International Standards of the Simplified Customs Control of Citizens When Crossing the Customs Border of Ukraine", Public Policy and Ecnomic Development, no. 2, pp. 93-98, 2014. doi: 10.14746/pped.2014.2.14

[4] J. BIRKS, "Scintillation Counters", Soil Science, vol. 77, no. 2, p. 171, 1954. doi: 10.1097/00010694-195402000-00024.
[5] H. Heney, "A.N.S.W. Experiment in Technique Demonstration", Australian Journal of Social Work, vol. 5, no. 2, pp. 4-6, 1951. doi: $10.1080 / 03124075108522453$

[6] L. Bignell et al., "Measurement of radiation damage of water-based liquid scintillator and liquid scintillator", Journal of Instrumentation, vol. 10, no. 10, pp. P10027-P10027, 2015. doi: 10.1088/17480221/10/10/p10027.

[7] F. Pönisch et al., "Liquid scintillator for 2D dosimetry for high-energy photon beams", Medical Physics, vol. 36, no. 5, pp. 1478-1485, 2009. doi: 10.1118/1.3106390.

[8] L. Archambault et al., "Verification of proton range, position, and intensity in IMPT with a 3D liquid scintillator detector system", Medical Physics, vol. 39, no. 3, pp. 1239-1246, 2012. doi: 10.1118/1.3681948.

[9] L. Oberauer, "Liquid Scintillator Detectors", Nuclear Physics B Proceedings Supplements, vol. 235-236, pp. 198-204, 2013. doi: 10.1016/j.nuclphysbps.2013.04.011.

[10] L. Lança and A. Silva, "Digital radiography detectors - A technical overview: Part 1", Radiography, vol. 15, no. 1, pp. 58-62, 2009. doi: 10.1016/j.radi.2008.02.004.

[11] L. Lança and A. Silva, "Digital radiography detectors - A technical overview: Part 2", Radiography, vol. 15, no. 2, pp. 134-138, 2009. doi: 10.1016/j.radi.2008.02.005.

[12] S. Schweizer and J. Johnson, "Fluorozirconate-based glass ceramic Xray detectors for digital radiography", Radiation Measurements, vol. 42, no. 4-5, pp. 632-637, 2007. doi: 10.1016/j.radmeas.2007.01.056.

[13] A. Chavaillaz, A. Schwaninger, S. Michel and J. Sauer, "Automation in visual inspection tasks: X-ray luggage screening supported by a system of direct, indirect or adaptable cueing with low and high system reliability", Ergonomics, vol. 61, no. 10, pp. 1395-1408, 2018. doi: 10.1080/00140139.2018.1481231.

[14] M. Vendel, S. Dangal, J. Coppens, S. Hiemstra-van Mastrigt and P. Vink, "Effects of a hand luggage guiding system on airplane boarding time and passenger experience", International Journal of Aviation, Aeronautics, and Aerospace, 2019. doi: 10.15394/ijaaa.2019.1333.

[15] F. Bohapov, "Simulation of X-Ray Television System Output Signal Based on CMOS-Matrixes", Electronic and Acoustic Engineering, vol. 3, no. 4, pp. 53-58, 2020. doi: 10.20535/26170965.2020.3.4.200608. 